\title{
Migraine madness: recurrent psychosis after migraine
}

\author{
G N Fuller, A Marshall, J Flint, S Lewis, R J S Wise
}

\begin{abstract}
A 69 year old man with longstanding migraine with aura had four episodes of psychosis lasting 7-28 days during a 17 year period. During attacks he had formed visual hallucination and delusions, including reduplicative paramnesia. His mother was similarly affected. His EEG showed symmetrical frontal delta waves. The time course and EEG changes are similar to acute confusional migraine. The reduplicative paramnesia suggests a focal non-dominant hemisphere dysfunction.
\end{abstract}

(F Neurol Neurosurg Psychiatry 1993;56:416-418)

A wide variety of auras have been described in classical migraine (migraine with aura).' Visual phenomena both positive and negative are frequent, usually lasting less than one hour and occurring either before, coincident with or at different times from the headache. ${ }^{12}$ Much less common are aura that involve higher mental function ${ }^{3}$ such as confusional states, particularly seen in children, ${ }^{4}$ temporal lobe phenomena, ${ }^{5}$ and dysphasia. ${ }^{5}$

Dysphrenic migraine is a term used to refer to mental changes or "psychic alterations" associated with migraine. ${ }^{3}$ The term has been used to encompass a wide range of phenomena including twilight states, hallucinations, somnambulism, suicidal attempts, ideas of reference, religious and persecutory delusions, confusional states and stupor. ${ }^{3}$ Psychosis is rarely reported ${ }^{267}$ and the form of the psychosis is rarely described in detail. We describe a man with recurrent episodes of psychosis with prominent reduplicative paramnesia (a delusion that familiar people, places or objects have been replaced by a double) associated with migraine.

Neurology, Charing Cross Hospital,

Fulham palace Road, London W6, UK

G N Fuller

A Marshall

R J S Wise

Department of Psychiatry, Charing Cross Hospital,

Fulham palace Road,

London W6, UK

J Flint

$S$ Lewis

Correspondence to:

Dr. Fuller

Received 10 April 1992

and in revised form

17 July 1992

Accepted 29 July 1992 Case report
A 69 year old man with longstanding migraine with aura presented with persecutory beliefs and formed visual hallucinations. His wife reported that 3 days before he had been normal. He had then gone to bed complaining of severe bifrontal headache associated with vomiting. The next day the headache continued. On waking on the third day the headache had resolved and he complained that his wife and brother-in-law were changing before his eyes, that their arms lengthened and they each had only one eye. He said familiar things looked strange, for example he thought the original house had been replaced by a cleverly produced copy. The next day he started seeing threatening words written on the walls and had refused to enter certain rooms because of evil in them. He had at times seemed confused and had fallen 5-6 times. He had no abnormal movements.

He had suffered from migraine with aura since the age of 16 . The aura usually began with tingling in both lips and dysarthria followed by tingling of his left arm, followed by flashing lights in both eyes and after about 30 minutes a right sided throbbing headache. These attacks had occurred at 3-6 monthly intervals. At the age of 53 he had a migrainous headache followed within 24 hours by an episode of paranoid psychosis that lasted 3 weeks with full recovery. Two years later, when well, he had an EEG which showed a low voltage post-central activity at $6-8 \mathrm{~Hz}$ with a moderate amount of slower waves at 4-6 Hz bilaterally. Some episodic anterior delta waves were seen on overbreathing.

At 64 he was admitted to a psychiatric hospital with a similar episode. This began with a migrainous headache and was followed, within 24 hours, by formed persecutory visual and auditory hallucinations. He called the police twice in one evening when he saw 100 burglars in the front garden. He was initially disorientated in time. $\mathrm{He}$ returned to normal after 7 days. An EEG performed 1 month after the attack was similar to that performed when he was 55 except that there were more frequent episodes of bisynchronous $2-3 \mathrm{~Hz}$ delta activity at $20-100 \mathrm{uV}$. The delta waves were not seen on an EEG 3 months later. At the age of 65 he had a further episode of paranoid psychosis within 24 hours of a migrainous headache that lasted 14 days.

$\mathrm{He}$ had been treated for hypothyroidism since the age of 65 . His mother had migraine with aura and recurrent episodes of migraine followed by paranoid hallucinatory episodes. He had no history of epilepsy and drank alcohol infrequently.

On examination he was agitated and with a 
example, he said he saw doctors' arms elongating. He failed to recognise familiar faces. He had ideas of reference and bizarre delusions that his wife and brother-in-law had been killed, that the ward staff were systematically butchering other patients on the ward, that the ward had moved to another location "towed across country by a motor tractor" (reduplicative paramnesia). There were no first rank symptoms of schizophrenia. Cognitive examination showed orientation in time and place and mild impairment of recent memory only. General examination, and examination of the cranial nerves and the limbs were normal.

While he was under observation his visual hallucinations continued. He described "red and squirmy" piranha fish on the floor of his room and would try to stamp on them, after which they would disappear. He saw writing on the wall, and when asked what it said found he was too far from it. He then walked up to the wall and was able to read it out clearly.

CT brain scan was normal. Two EEGs performed within hours of his hallucinations, though neither during vivid hallucinations, both showed a low voltage featureless background composed mainly of $4-6 \mathrm{~Hz}$ theta activity at $5-25 \mathrm{uV}$. There were fairly frequent episodes of bisynchronous frontal $2-3 \mathrm{~Hz}$ delta activity up to $70 \mathrm{uV}$. Full blood count, ESR, biochemical tests and serological tests for syphilis were all normal or negative.

The hallucinations and altered mental state improved gradually lasting in total 10 days. His mental state became normal and he was able to recall the content of the hallucinations and recognised that they could not have been real. He remained well when reviewed 6 months after the episode.

Psychometry performed 6 months after the most recent attack revealed a full Wechsler adult intelligence scale of 105 . His poorest scores were on digit symbol, object assembly and block design where he performed at the dull average level. The Warrington Recognition Memory Test for words and faces $^{8}$ and the Unusual Views Tests $^{8}$ were within normal limits. His performance on the Benton Visual Retention Test $^{9}$ fell below acceptable limits. He made errors of size and placement relationships of the figures suggesting some inefficiency of spatial relationships.

\section{Discussion}

This man had 4 episodes in 17 years of psychosis with delusions and visual hallucinations lasting 7-28 days following a migrainous headache with normal mental state between attacks. He also had longstanding migraine with aura. ${ }^{1}$ His typical aura of left sided sensory disturbance suggested nondominant hemisphere involvement. $\mathrm{He}$ has had 4 episodes of psychosis each following within 24 hours of a severe migrainous headache without aura. The association of the psychoses with migraine is based on their temporal relationship. The episodes of psychosis have only occurred following migraine and were transient. Between attacks there is full recovery with insight. In addition there have been no features suggesting an alternative aetiology for the headaches or the psychoses, notably he had no history of epilepsy or alcohol abuse.

The description of a similar pattern of migraine with aura in the patient's mother, with the development of migraine followed by psychosis in the later part of her life suggests a link between the psychosis and migraine. It also suggests that it may be familial.

The types of the hallucinations described by our patient included some visual phenomena not infrequently seen in migraine aura, such as micropsia and macropsia ${ }^{10}$ as well as formed visual hallucinations which are rare..$^{20}$ The time course of the visual hallucinations and delusions in our patient are unusual in following the headache and lasting for several days.

Previously reported migraine psychoses have had a similar time course. $\mathrm{Klee}^{6}$ reported four patients with psychoses, with visual and auditory hallucinations and in one a distortion of body perceptions (she believed her legs to have been cut off) that lasted a few days. The episodes of psychoses followed the migraine attack and lasted several days. Eight out of nine members of a family with hemiplegic migraine described by Feeley et al' had either a psychotic episodes or confusional states, both of which lasted several days and followed migraine attacks.

A similar time relationship with the migraine attack is seen in acute confusional migraine when the confusion follows the migraine and may last for up to 5 days. ${ }^{11}$ The EEG abnormalities of intermittent frontal delta waves seen in this patient during and shortly after attacks resolved between attacks. Similar EEG findings have been reported in young patients with juvenile acute confusional migraine. ${ }^{12}$

One other phenomenon of particular interest is that of reduplicative paramnesia and delusional misidentification. Reduplicative paramnesia is a term coined by $\mathrm{Pick}^{13}$ to describe the delusion that a familiar person, object, place or even the patient's self was replaced by a double. The most well known variants of reduplicative paramnesia are delusional misidentification syndromes that involve the recognition of people. In Capgras' syndrome ${ }^{14}$ patients believe a familiar person is replaced by an identical double. In the syndrome of intermetamorphosis the patient believes someones appearance has radically changed to correspond with the appearance of someone else. ${ }^{15}$ In another syndrome of delusional misidentification, the Frégoli syndrome, the patient misidentifies strangers as being a familiar person in disguise. ${ }^{15}$ Reduplicative paramnesia of inanimate objects is less often recognised. ${ }^{10}$ Our patient believed that his house had been replaced, thought his surroundings had been transported to an exactly similar site at a different 
location and failed to believe that his wife was his wife. The first two are delusions of replacement of objects and surroundings and it is not clear whether the last represents prosopagnosia or delusional misidentification.

Capgras' syndrome has been described previously in two patients with migraine. ${ }^{1718}$ Both patients had common migraine and developed a single episode of delusional misidentification following a migraine attack ${ }^{18}$ or an episode of vomiting associated with a right hemiparesis attributed to vertebrobasilar migraine, though apparently without headache. ${ }^{17}$ We are not aware of reports of other delusional misidentification syndromes, such as the Frégoli syndrome or intermetamorphosis, in migraine.

It has been proposed that reduplicative paramnesia arises from a disconnection between the non-dominant visual association cortex and the limbic structures associated with memory. ${ }^{15} 1920$ This provides a potential discrete site for the disturbance of function that occurred in our patient and is in keeping with the mild neuropsychological deficit found. The pathophysiology of the disturbance is unknown but has many features in common with other delayed disturbances of higher function such as acute confusional migraine and hemiplegic migraine.

1 Headache Classification Committee of the International Headache Society, Classification and diagnostic criteria for headache disorders, cranial neuralgias and facial pain. Cephalalgia 1988;8(Suppl 7):19-28.

2 Saciss O. Migraine: understanding the common disorder. London: Pan Books, 1985.

3 Bruyn GW. Migraine equivalents. In: Clifford Rose F, ed. Handbook of Neurology, vol 4, Headache. Amsterdam: Elsvier Science Publishers, 1986 .

4 Gascon G, Barlow C. Juvenile migraine, presenting as an acute confusional state. Pediatrics 1970;45:628-35.

5 Ardilla A, Sanchez E, Neuropsychologic symptoms in migraine syndrome. Cephalalgia 1988;8:67-70.

6 Klee A. A clinical study of migraine with particular reference to the most severe cases. Copenhagen: Munksgaard, 1968.

7 Feeley MP, O'Hare J, Veale D, Callaghan N. Episodes of acute confusion or psychosis in familial hemiplegic migraine, Acta Neurol Scand 1982:65:369-75.

8 Warrington EK. Recognition Memory Test for words and faces. Windsor: NFER Nelson, 1984.

9 Benton AL. The Visual Retention Test. New York: The Psychological corporation, 1955.

10 Klee A, Willanger R, Disturbances of visual perception in migraine. Acta Neurol Scand 1966;42:400-14.

11 Pietrini V, Terzano MG, D'Andrea G, Parrino L, Canaanzi AR, Ferro-Milone F. Acute confusional migraine: Clinical and electroencephalographic aspects. migraine: Clinical and electr

12 Walser $H$, Isler H. Frontal intermittent rhythmic delta wave activity, impairment of consciousness and migraine. Headache 1982;22:74-80.

13 Pick A, Clinical Studies III, On reduplicative paramnesia, Brain 1903;26:260-7.

14 Capgras J. Reboul-L'achaux J, Illusion des sosies dans un délire systématisé. Chronique Bull Societe Clinique de Medecine Mentale 1923;2:6-16.

15 Staton RD, Brumback RA, Wilson H. Reduplicative paramnesia: a disconnection syndrome of memory. Cortex 1982;18:23-36.

16 Anderson DN. The delusion of inanimate doubles: Implications for understanding the Capgras phenomenon, Br $¥$ Psychiat 1988;153:694-9.

17 MacCallum WAG. Capgras symptoms with an organic basis, Br $\mathcal{F}$ Psychiat 1973;123:639-42.

18 Bhatia MS. Capgras syndrome in a patient with migraine Br f Psychiat 1990;157:917-8.

19 Lewis S. Brain imaging in a case of Capgras' syndrome, Br F Psychiat 1987;150:117-121.

20 Ellis HD, Young AW. Accounting for delusional misidentifications. Br $\mathcal{F}$ Psychiat 1990;157:239-48. 